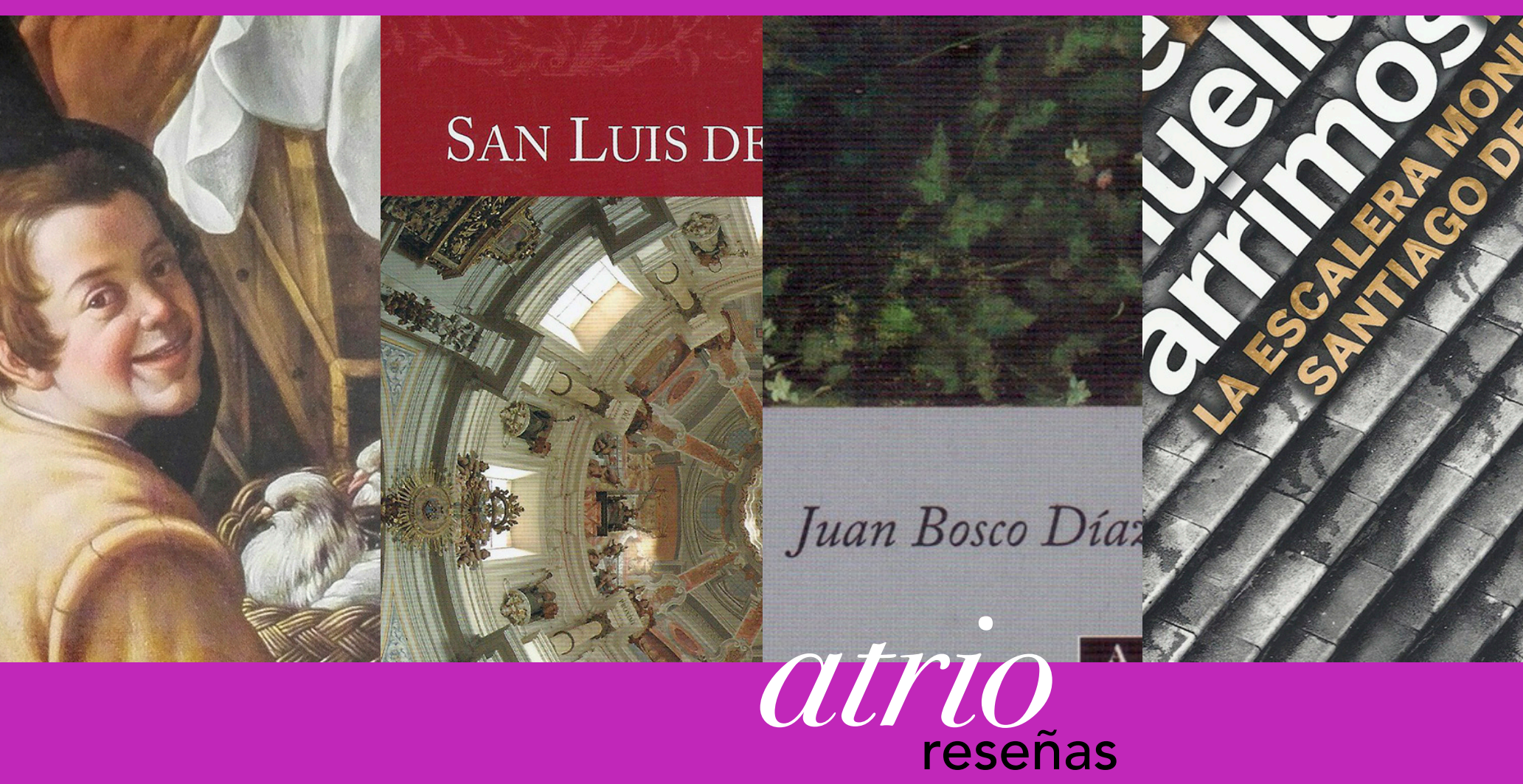




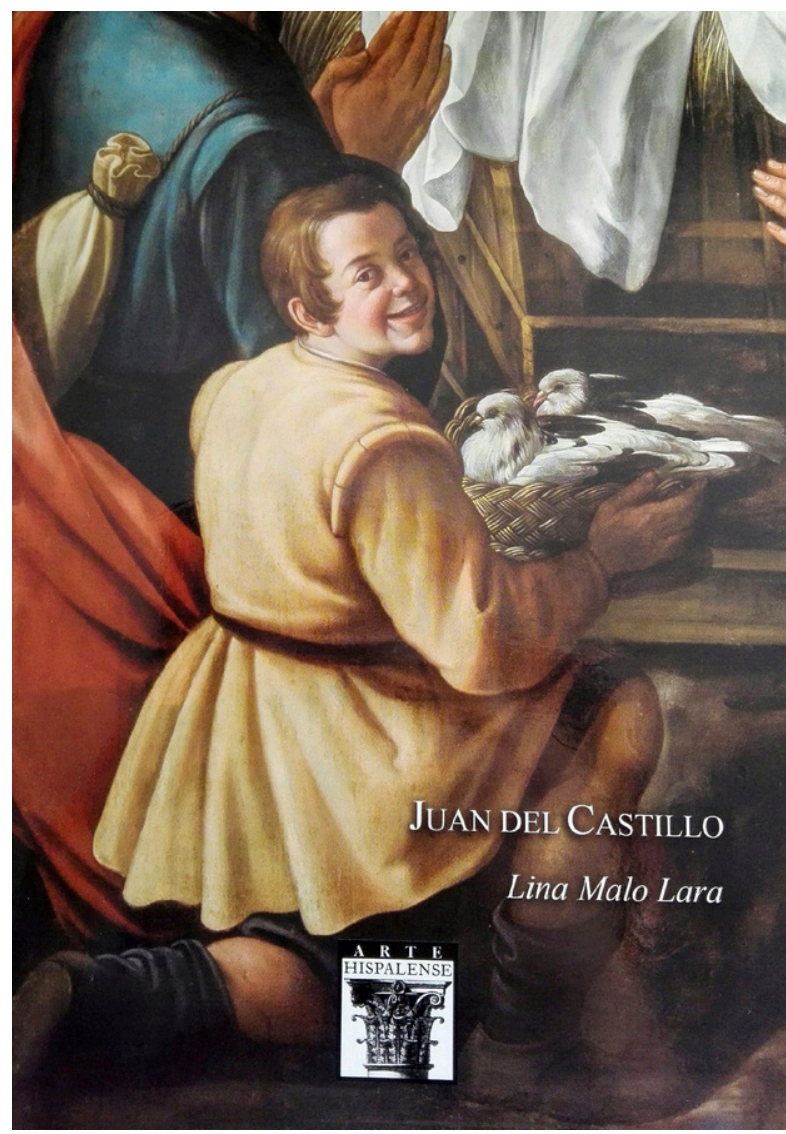

Lina MALO LARA

\section{Juan del Castillo, pintor en la Sevilla del siglo XVII}

Sevilla, Diputación Provincial, Arte Hispalense n. ${ }^{\circ}$ 113, 2017. 171 págs.

ISBN: 978-84-7798-414-6

Dentro de la colección Arte Hispalense, con un sencillo y claro lenguaje, Lina Malo Lara (Q.E.P.D.) nos ofrece un trabajo de investigación que acercará, tanto a los especialistas como a los no instruidos, a una realidad -el quehacer artístico y social de un pintor sevillano en el Siglo de Oro-, donde Juan del Castillo, tradicionalmente conocido por ser el maestro de Murillo, fue un interesante pintor, inmerso en un contexto de endogamia gremial, dentro del cual, establecer relaciones de amistad con otros ar- tistas significaba la obtención o el traspaso de grandes encargos.

El trabajo que el lector tiene entre sus manos es el resultado de una larga y rigurosa trayectoria investigadora, cuyos frutos sirven ahora para mostrarnos los múltiples entresijos de la actividad artística de Castillo, la evolución de su estilo o sus importantes vínculos sociales. Cimentado sobre un gran corpus documental, la autora arroja un buen número de nuevas e interesantes aportaciones, dividiendo la obra en seis apartados que abarcan, desde un recorrido cronológico por la historiografía relativa al artista y su perfil biográfico-estilístico, hasta un detallado análisis evolutivo de su producción artística, que se ilustra con un pequeño catálogo de carácter antológico.

Para comenzar, la autora nos ofrece un recorrido historiográfico a modo de estado de la cuestión. Así, se recogen las obras fundamentales que desde el siglo XVIII con Palomino, hasta la actualidad, han tratado la figura del artista. A lo largo del mismo, Lina Malo sitúa el foco sobre una serie de noticias preexistentes que bien serán refutadas, desmentidas, corregidas o ampliadas a lo largo del presente trabajo, constituyendo un ejercicio de gran rigor científico, que sumado a una inteligente interpretación de los documentos, revelará nuevos enfoques sobre la semblanza del artista.

A continuación, el segundo apartado -probablemente el más importante- se dedica al perfil biográfico, donde va a residir uno de los elementos más destacables de la investigación de la doctora Malo, puesto que, si bien, gran cantidad de los aspectos aquí tratados ya nos eran conocidos, se van 
a aportar numerosas novedades que vienen a llenar vacíos documentales y clarifican la trayectoria vital y profesional del biografiado. Así, a pesar de incidir en la carencia de información sobre los primeros años de existencia del pintor -entre otros datos-, la detenida lectura y el enfoque metodológico de la autora, cercano a un estudio sociológico del artista, permiten intuir o relegar a un segundo plano la relevancia de estas noticias. Como venimos diciendo, el método de análisis empleado permite reconstruir a lo largo del capítulo las redes tanto familiares como de amistad del pintor, llevándonos más allá de la simple enumeración documental. Reside pues, el principal aporte, en observar cómo actúa Juan del Castillo a la hora de establecer relaciones sociales que acaban conectándole con otros miembros activos y relevantes en la industria pictórica, como pudieron ser Vasco Pereira, Antonio Pérez, Pablo Legot o los Cano -Miguel y Alonso-, permitiendo esta endogamia profesional prosperar artísticamente al protagonista de nuestro libro. Destacable es, sin duda, la aportación de más de quince documentos inéditos que vienen a reforzar más aún, si cabe, el conocimiento de uno de los asuntos más desarrollados por la historiografía tradicional: su estrecho vínculo con la familia de Murillo y la influencia de estos lazos para el futuro aprendizaje de este bajo el magisterio de Castillo. Finalmente, para ilustrar todas las relaciones aquí aducidas, se adjunta un revelador árbol genealógico, del que podemos deducir la integración de Castillo en la que podríamos denominar una saga de pintores.

Prosigue la obra con una tercera sección dedicada a establecer la cronología del pintor a través de toda la documentación conocida actualmente, algo característico en muchas de las publicaciones monográficas de esta serie. Sin embargo, no podemos pasar inadvertido el papel de la autora en esta recopilación documental, puesto que de las casi ochenta noticias que se recogen, alrededor de una veintena han sido aportadas por Lina Malo a lo largo de su trayectoria investigadora. Si atendemos a que el nacimiento del pintor sevillano ha de situarse en fechas próximas a 1593, el marco cronológico, que abarca desde 1611 a 1657 -año de fallecimiento del artista-, nos revela una trayectoria profesional netamente documentada.

El siguiente apartado, centrado en el estilo artístico de Juan del Castillo, se dedica tanto a la formación del pintor como a la configuración de su identidad estilística, ligada a la raigambre artística de sus ascendientes. En consecuencia, el estilo de nuestro biografiado se revela ciertamente continuista, puesto que se inserta a medio camino entre el tardomanierismo y el incipiente naturalismo de las primeras décadas del siglo XVII. De igual modo se desgranan, desde las hipótesis sobre su primer aprendizaje, hasta la formación visual que hubo de obtener indirectamente de artistas como Vasco Pereira, a través de su suegro Antonio Pérez Murillo, quien había heredado la que en su momento fue la biblioteca más grande poseída por un artista en la capital hispalense. Si atendemos, pues, tanto a los útiles que poseía en su obrador -según consta en su inventario de bienescomo al evidente empleo de modelos visuales basados en grabados de origen flamenco e italiano, entre otros, Lina Malo nos descubre a un artista de limitadas inquietudes. No obstante, Castillo se erige como un pintor de considerable calidad artística, que aun con un limitado talento es capaz de encontrar una relativa estabilidad profesional a causa de la enorme demanda que supone dotar de programas iconográficos a los retablos de numerosos templos.

Llegados al quinto y penúltimo capítulo de esta obra, constituye un elemento fundamental el pormenorizado análisis de la producción artística conservada o documentada, que la autora acomete de una manera ordenada, basada en la división de etapas previamente establecida por Valdivieso y Serrera, que divide en hasta cuatro momentos la producción del pintor y su correspondiente evolución estilística. Asimismo, se nos presenta a un artista, cuya dinámica de obtención de encargos se liga estrechamente a sus 
ya mencionados círculos sociales en el gremio de pintores, siendo beneficiario, por ejemplo, de multitud de traspasos de obras por parte de creadores cercanos como Pablo Legot o los Cano, figuras dominantes del panorama sevillano. De este modo, todas las obras conservadas o encargos conocidos se analizan iconográficamente, amén de introducirnos, con especial énfasis, en la dinámica por la cual el pintor obtenía el encargo y firmaba su correspondiente concierto, profundizando en su proceso creativo y localizando las fuentes visuales empleadas en cada uno de sus lienzos. Todo lo anterior se completa finalmente con un pequeño e interesante catálogo en el que se comentan una serie de hasta dieciséis obras del autor -algunas inéditas hasta ahora- que sirven para ejemplificar todos los aspectos analizados.

En conclusión, nos encontramos ante una importante aportación al estudio de la pintura sevillana del siglo XVII, que constituye un ejemplo metodológico sobre cómo hemos de continuar redescubriendo a los artistas secundarios del seiscientos hispalense. Una mirada histórico-social de los artistas, que complete la visión historiográfica. Con todo ello, Lina Malo ha conseguido que Juan del Castillo deje de ser un mero maestro de grandes pintores, para mostrarnos a un hábil creador, que a través del entorno familiar y gremial, llegó a ser uno de los más relevantes de su ciudad. 